\title{
DESIGN-BUILD AND DESIGN-BID-BUILD IN CONSTRUCTION- A COMPARATIVE REVIEW
}

\author{
Titouan Plusquellec ${ }^{1}$, Nadia Lehoux ${ }^{2}$, and Yan Cimon ${ }^{3}$
}

\begin{abstract}
This paper aims at synthesizing relevant findings about the Design-Build (DB) construction delivery system from previous studies. It focuses especially on cost, schedule, quality, and various sustainability aspects associated with a construction project, as they are widely used as performance indicators in this industry. This work has been done through a literature review and a content analysis, focusing on papers comparing Design-Build to the classical Design-Bid-Build delivery system. The results of the literature review show that Design-Build outperforms Design-Bid-Build in terms of cost and schedule growth as well as in terms of delivery speed, all for a similar quality. Furthermore, it may suggest that Design-Build could help in reaching highly sustainable goals while being a key step in the implementation of lean construction. This study might allow owners to save time in their investigation about the performance of Design-Build, and even lead them to reconsider their project delivery system choice when planning for new project launches.
\end{abstract}

Keywords: Design-Build; Design-Bid-Build; Construction Delivery Systems; Comparative Review.

\section{INTRODUCTION}

The way construction projects are conducted and managed has evolved considerably over the years. Indeed, as technology progressed, the complexity of projects soon reached a point where it exceeded the grasp of a single expert. The increasing complexity led the stakeholders of a construction project to specialize, thereby sequencing the project's organization (Sanvido et al., 1992). This evolution led to what is currently known as the classical delivery method, where the owner contracts a team of architects and engineers to design the building and then elects a contractor following the lowest bidder rule.

However, this classical Design-Bid-Build (DBB) delivery system is still far from perfect since most of the construction projects have to face some cost increases and schedule overruns, which can be really harmful for the owner. Moreover, in some parts of the world, as is the case in the Province of Quebec, Canada, the construction industry is currently facing a drop in activity (CCQ, 2015). The lack in efficiency shown by the classical method promotes the use of alternative delivery methods such as Design-Build (DB), characterized by a single contract with an entity dispensing both the design and the construction of the building. Similar conclusions led to the development of Lean Construction, which aims to optimize the performances at a project level (Forbes \& Ahmed, 2011).

Since its first definition on the early 1990s, Design-Build has been gaining market share, reaching nearly 40\% in the US in 2014 (RSMeans, 2015). It makes this delivery

Graduate Student, CIRCERB, Faculty of Science and Engineering, Université Laval, Québec, QC, Canada; titouan.plusquellec.1@ulaval.ca

2 Associate Professor, Ph.D. CIRCERB; CIRRELT; Faculty of Science and Engineering, Université Laval, Québec, QC, Canada; Nadia.Lehoux@gmc.ulaval.ca

3 Professor, Ph.D. CIRRELT; Faculty of Business Administration, Université Laval, Québec, QC, Canada; Yan.Cimon@fsa.ulaval.ca 
system one of the most significant trends in design and construction (DBIA, 2016). As it becomes even more important, the Design-Build delivery system is the subject of numerous research efforts that try to determine whether this mode is more efficient than the classical method. To do so, each study focuses on specific aspects of a construction project such as cost and schedule performance, single or multiple owners, and the type of building erected. However, the literature lacks a study synthesizing all the observations and the findings found about Design-Build performance in comparison with Design-BidBuild; which represents the goal of this study. Thus, this paper aims at synthesizing the knowledge gathered from previous studies about the performance of Design-Build compared to the classical Design-Bid-Build delivery system.

The paper is divided as follows: in Section 2, some preliminary concepts are defined. In Section 3, the research method followed is described while in Section 4, the results are presented. A discussion and a brief conclusion complete the paper.

\section{PRELIMINARY CONCEPTS}

As this study focuses on the comparison between Design-Build and Design-Bid-Build, these are the definitions used to characterize those project delivery methods based on the first comparative study proposed by Konchar and Sanvido (1998):

"Design-Build (DB) is a project delivery system where the owner contracts with a single entity to perform both design and construction under a single design-build contract. Contractually, design-build offers the owner a single point of responsibility for design and construction services. Portions or all of the design and construction may be performed by a single design-build entity or by a selection of specialized workers. In some cases, all of the activities may be subcontracted to other companies (Konchar et al., 1998: page IX)."

"Design-Bid-Build (DBB) is a project delivery system where the owner contracts separately with a designer and a constructor. The owner normally contracts with a design company to provide "complete" design documents. The owner or owner-agent then usually solicits fixed price bids from construction contractors to perform the work. One contractor is usually selected and enters into an agreement with the owner to construct a facility in accordance with the plans and specifications (Konchar et al., 1998: page IX)."

Even though the performance triangle time-cost-quality is not necessarily the best way to determine the success of a project (Atkinson, 1999), it is still the tool most used by the authors to compare the two construction delivery systems. Because these criteria remain the most representative way to synthesize results from different studies, this paper will mainly use the same indicators. Quality being a subjective measurement, there is hardly a unique indicator to measure it. Thus, past research generally used surveys to collect data and then emit global conclusions about the behaviour of each delivery system concerning quality performance. The quality of constructed facilities, the compliance with construction specifications or the conformity to user expectations are some of the indicators commonly used for quality measurement.

\section{RESEARCH METHOD}

\subsection{Test}

\subsubsection{Test again}

All of the information used to compare the two construction systems was gathered through a structured literature review (see Cooper (1998) for more details). 
The first step was to identify key articles related to the subject using two online databases: Web of Science and Compendex. In particular, a combination of the keywords "Design-Build"; "Design-Bid-Build"; "Construction Delivery Systems", "Comparative analysis" were exploited to find relevant papers for the research. Once those articles were found, the authors focused on their lists of references to identify other interesting articles related to the subject (i.e., backward snowballing, see Wohlin (2014)). The authors took great care to ensure that validity and reliability criteria were met (Carmines \& Zeller, 1979). In terms of validity, they ensured their concepts met the agreed-upon definitions in both academic and practice-related literature. Furthermore, they ensured reliability by searching with consistent keywords in leading commercial databases that are well known for the quality of their contents, thus ensuring that researchers in the field could replicate this research. Most of the articles identified in that way dealt with empirical and statistical analysis, using data from construction projects already delivered. The findings of those studies were therefore classified and analyzed to better capture the performance of each type of construction delivery system, as presented in the next section, which details the content of those comparative studies.

\section{RESULTS}

The first search on Web of Science yielded a list of 83 articles. Among all the articles found, 16 relevant papers comparing Design-Build and Design-Bid-Build were retained. From those 16 studies, 11 focused on the cost-schedule-quality performance for the two project delivery systems. These 11 papers used data from a total of 1,609 construction projects, 636 projects concerning the DB method and 973 projects being related to the DBB approach. Moreover $98 \%$ of the project sample was located in the United States. The authors also observed that military construction projects represented $64 \%$ of the sample. The comparative study written by Konchar and Sanvido (1998) was the research most cited.

In 1998, Konchar and Sanvido published one of the main studies between different project delivery systems: Design-Bid-Build, Construction Management at Risk (CMR), and Design-Build. These systems were empirically compared through the results of numerous projects conducted in the United States, regarding their cost, schedule, and quality performances. Data concerning cost and schedule were directly extracted from project metrics while quality was evaluated based on a questionnaire sent to the project owners. In particular, the study gathered data from 351 projects, from which $44 \%$ were DB, $33 \%$ DBB, and 23\% CMR. The projects concerned different building categories, namely: Light industrial, Multi-storey dwelling, Simple office, Complex office, Heavy industrial, and High-technology facilities. The researchers also compared the performance of each delivery system through three univariate statistical analyses respectively focusing on cost, schedule and quality. They ranked the delivery systems following the facility type and the owner type. They finally conducted a multivariate analysis to identify variables that accounted for the greatest proportion of variation concerning unit cost, construction speed, delivery speed, cost growth, and schedule growth. The authors concluded that projects administered using the Design-Build project delivery system can achieve significantly improved cost and schedule advantages while quality achieved using DB is equal or sometimes higher than the one obtained from the other delivery systems studied.

Another study, focusing on military construction, was conducted in 2009 by Rosner et al. with data from the Air Force military construction program. This study used a large sample of projects encompassing $278 \mathrm{DB}$ projects and $557 \mathrm{DBB}$ projects, for a total of 835 projects. These projects included various types of facilities, from storage to more complex 
operational facilities or even airfield pavement. The performance was evaluated based on cost and schedule indicators, but the number of modifications per million dollars was also taken into account. A statistical analysis showed significant results in favour of DesignBuild in terms of cost growth and modification per million, but the DBB achieved the advantage in terms of total project time. This study concluded that DB was most suited for 7 out of the 9 facility types studied. For the 2 other types of facility, storage and maintenance units, the statistical analysis did not show a significant difference. Besides the statistical analysis, the large number of projects used enabled the authors to represent the evolution of the use of design-build over time, showing a notable increase around $1999 / 2000$, when the use of DB jumped from $18 \%$ to $48 \%$.

In 2016, a study was published by El Asmar et al., but unlike most of the other studies, it did not evaluate the delivery systems using only cost, schedule, and quality metrics. Indeed, the purpose of this study was to adapt the Quarterback Rating technique to project ranking in order to compare the performance of different construction systems, which led to the "Project Quarterback Rating". The advantage of the method is that it ranks the different systems using only one output metric. The authors decided to compare 4 delivery systems: DBB, DB, CMR, and Integrated project delivery, through data from 35 projects. The project quarterback rating allowed the researchers to take a large number of indicators into account, which were divided into 7 categories: customer relations, safety, schedule, cost, quality, profit, and communication. Their method led them to emit a ranking of the four compared delivery systems: Integrated project delivery finished first, followed by Design-Build, then Construction Management at Risk, and finally Design-Bid-Build.

As described above, most of the studies used an empirical approach to compare the different delivery systems based on cost, schedule, and quality performances. Other studies that rather compared the delivery systems based on their ability to deliver sustainable projects were also found. The level of sustainability reached by a project was generally evaluated following the LEED ranking which is recognized as the international mark of excellence for green building in 132 countries (CaGBC, 2016).

In 2009, Molenaar et al. published a report aiming to determine whether project delivery methods influence an owner's ability to achieve its sustainability goals. To do so, the authors gathered information about 230 projects: $53 \mathrm{DB}, 54 \mathrm{DBB}$, and $123 \mathrm{CMR}$, using a questionnaire survey sent all over the United States. The project sample was also divided by contract type used in each delivery system. Based on the analysis of their survey responses, the researchers concluded that if the owner wants to maximize sustainability within an available budget, CMR and DB provide the greatest likelihood of success. The study also revealed that integration is necessary to seek a high level of LEED ranking.

Another element on which the different construction delivery systems were compared concerns the legal aspect. Indeed, a study written by Pishdad-Bozorgi et al. in 2012 compared $\mathrm{DB}$ and $\mathrm{DBB}$ from the standpoint of claims. Using a literature review and a series of interviews, the authors tried to determine the influence of $\mathrm{DB}$ over the number of claims between the owner and the contractor. Results showed that the number of claims emitted by the contractor decreased for DB systems, especially when it dealt with changes in contract documents. The owner's claims also tended to decrease, especially the ones dealing with cost over-run and schedule delays. Nevertheless, claims about work quality might increase for DB systems depending on the level of commitment of the owner and the design-build team expertise. 


\section{DISCUSSION}

Based on what was found in the literature, it becomes possible to highlight some aspects of the duality between Design-Build and Design-Bid-Build. First, we can see that, at least in the US, Design-Bid-Build is still the main delivery system used, with $58 \%$ in 2014 against $38 \%$ for DB (RSMeans, 2015). Moreover, it seems that military construction is one of the principal users of Design-Build as it reached 48\% of the MILCON use in 2009 (Rosner, Thal, \& West, 2009). This may justify that 4 of the 11 empirical studies listed focused on military constructions. This goes along with the ease of access to military project data.

It is also interesting to note that most of the papers compared the different construction delivery systems using cost, schedule, and quality performance indicators. A summary of the studies using this kind of evaluation can be found in Table 1. Only the indicators included in most of the papers are presented (i.e., cost growth, unit cost, schedule growth, and delivery speed). Due to the heterogeneity of the units used to describe the unit cost and the delivery speed, no mean could be calculated for these two indicators; this heterogeneity is a consequence of the different types of buildings studied in each research. As quality cannot be efficiently evaluated with quantitative values, only the general conclusions of the studies which tackled this issue are represented in the table.

When looking at this recapitulative table, it can be noted that the DB system seems more reliable concerning the estimated budget and schedule. In particular, a mean cost growth $2 \%$ lower and a mean schedule growth $8 \%$ lower than the ones obtained for the DBB system can be observed, even though some studies punctually showed results in disfavour of DB. It is also important to note that every study providing value for the mean delivery speed tends to agree on the fact that $\mathrm{DB}$ is faster than the classical delivery system. The only point where Design-Build does not outperform Design-Bid-Build is the unit cost, as most of the studies found almost no differences concerning this indicator.

When looking at quality, authors pointed out that DB quality performance was better or similar to the quality performance of DBB projects. There is however some uncertainty attributable to the subjective nature of quality, which makes it difficult to measure without perceptual influences. But a conservative interpretation could be that DB performs at least as well as DBB in terms of quality. The literature also highlighted the capability of DB to deliver sustainable projects. Every study written on that subject agreed with the fact that project integration facilitates the reach of higher sustainable goals. They also confirmed that $\mathrm{DB}$ can achieve a greater project team integration than DBB. However, they also mentioned that the best delivery system in terms of integration, and therefore in terms of sustainability, was the Integrated Project Delivery (IPD).

The Integrated Project Delivery also seams to be the system of choice to reach efficient lean construction methods (Forbes \& Ahmed, 2011). However, DB and IPD are similar in many ways. We can consider DB as a first step to reach IPD because the selection of the Design-Builder is still mainly based on cost while IPD goes a little further by taking qualification consideration into account. Moreover, even though DB promotes integration when conduction the project, this integration mainly happens between the design team and the contractor. With IPD, the owner is also fully involved over the life of the project (Haskell, 2017). DB can therefore be seen as an intermediate step to reach the requirement of lean construction in terms of integration and internal communication. 


\section{CONCLUSION}

In this article, a synthesis of previous studies comparing Design-Build and Design-BidBuild has been proposed. By combining and analyzing the different results of these studies, a clear advantage in favour of Design-Build was found, as it seems to outperform the classical delivery system in each criterion typically used for measuring a construction project performance, except for the unit cost. In other words, it seems that DB is a faster and more reliable construction delivery system, leading to a slightly lower claim rate.

And as even more construction projects try to achieve sustainable goals, its relative integration may represent an advantage. However, it appears that most of the studies used in this research were based on US projects, which may not represent the situation of DB elsewhere in the world. Future work could certainly involve more extensive research with more keywords and ideally more than one language to compare the findings with a larger international sample. This paper represents a synthesis of the knowledge gathered around Design-Build in comparison with Design-Bid-Build, which may help further researchers in their literature reviews. This study might also allow owners to save time in their investigation about the performance of $\mathrm{DB}$, and even lead them to reconsider their project delivery system choice when planning for new project launches. 
Table 1: Summary of the empirical studies.

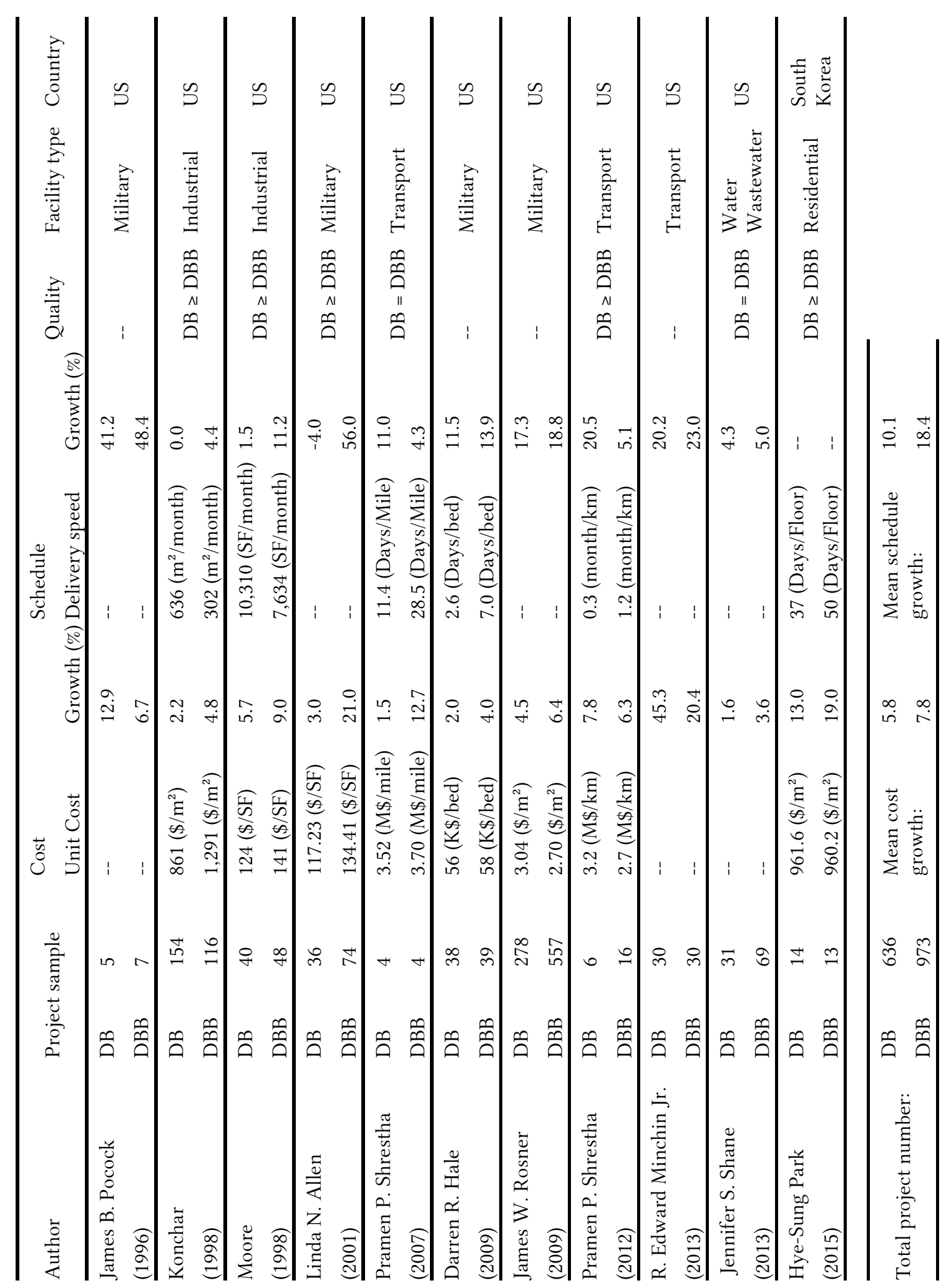




\section{REFERENCES}

Allen, L. N. (2001). Comparison Of Design-Build To Design-Bid-Build As A Project Delivery Method.

Asmar, M. E., Hanna, A. S., \& Loh, W.-Y. (2016). Evaluating Integrated Project Delivery Using the Project Quarterback Rating. Journal of Construction Engineering and Management, 142(1). doi:10.1061/(ASCE)CO.1943-7862.0001015

Atkinson, R. (1999). Project management: cost, time and quality, two best guesses and a phenomenon, its time to accept other success criteria. International Journal of Project Management, 17(6), pp. 337-342.

CaGBC. (2016). LEED - Leadership in Energy and Environmental Design. (Canada Green Building Council) Retrieved 2016, from Conseil du bâtiment durable du Canada Québec: http://batimentdurable.ca/construction-developpement-durable/leed

Carmines, E. G., \& Zeller, R. A. (1979). Reliability and validity assessment. Sage Publications.

CCQ. (2015). Revue de l'activité,4e trimestre 2014.

Cooper, H. M. (1998). Synthesizing Research: A Guide for Literature Reviews. SAGE.

DBIA. (2016). What is Design-Build? Retrieved 07 2016, from Design Build Institute Of America: http://www.dbia.org/about/Pages/What-is-Design-Build.aspx

Forbes, L. H., \& Ahmed, S. M. (2011). Modern Construction Lean Project Delivery and Integrated Practices. Boca Raton, FL: CRC Press, Taylor \& Francis Group.

Hale, D. R., Shrestha, P. P., Jr., G. E., \& Migliaccio, G. C. (2009). Empirical Comparison of Design/Build and Design/Bid/Build Project Delivery Methods. Journal of construction engineering and management, 135(7), pp. 579-587.

Haskell. (2017). Integrated Project Delivery Vs. Pure Design-Build. Retrieved 03 10, 2017, from http://haskell.com/getattachment/803de0de-153d-4cc5-9ca3e7e1a60e46fb/Integrated-Project-Delivery-vs-Pure-Design-Build

Konchar, M., \& Sanvido, V. (1998). A Comparison of United States Project Delivery Systems.

Minchin, R. E., Li, X., Issa, R. R., \& Vargas, G. G. (2013). Comparison of Cost and Time Performance of Design-Build and Design-Bid-Build Delivery Systems in Florida. Journal of Construction Engineering and Management, 139(10). doi:10.1061/(ASCE)CO.1943-7862.0000746.

Molenaar, K., Sobin, N., Gransberg, D., McCuen, T., Korkmaz, S., \& Horman, M. (2009). Sustainable, High Performance Projects and Project Delivery Methods.

Moore, S. D. (1998). A Comparison Of Project Delivery Systems On United States Federal Construction Projects. 
Park, H.-S., Lee, D., Kim, S., \& Kim, J.-L. (2015). Comparing Project Performance of Design-Build and Design-Bid-Build Methods for Large-sized Public Apartment Housing Projects in Korea. Journal of Asian Architecture and Building Engineering, 330, pp. 323-330.

Pishdad-Bozorgi, P., \& Garza, J. M. (2012). Comparative Analysis of Design-Bid-Build and Design-Build From the Standpoint of Claims.

Pocock, J. B., Hyun, C. T., Liu, L. Y., \& Kim, M. K. (1996). Relationship Between Project Interaction and Performance Indicators. Journal of Construction Engineering and Management, 122(2), pp. 165-176.

Rosner, J. W., Thal, A. E., \& West, C. J. (2009). Analysis of the Design-Build Delivery Method in Air Force Construction Projects. Journal of Construction Engineering and Management, 135(8), pp. 710-717.

RSMeans. (2015). Design-Build Project Delivery Market Share and Market Size Report Update for 2014 Non Residential and Multi-Family Activity.

Sanvido, V., Fenves, S., \& Wilson, J. (1992). Aspects Of Virtual Master Builder. Journal of Professional Issues in Engineering Education and Practice, 118(3).

Shane, J. S., Bogus, S. M., \& Molenaar, K. R. (2013). Municipal Water/Wastewater Project Delivery Performance Comparison. Journal of Management in Engineering, 29(3), pp. 251-258.

Shrestha, P. P. (2007). Performance Benchmarking of Large Highway Project.

Shrestha, P. P., O’Connor, J. T., \& Jr., G. E. (2012). Performance Comparison of Large Design-Build and Design-Bid-Build Highway Projects. Journal of Construction Engineering and Management, 138(1), pp. 1-13.

Wohlin, C. (2014). Guidelines for Snowballing in Systematic Literature Studies and a Replication in Software Engineering. EASE '14 Proceedings of the 18th International Conference on Evaluation and Assessment in Software Engineering. 